\title{
Aviation Turbulence: Dynamics, Forecasting, and Response to Climate Change
}

\author{
Luke N. Storer, ${ }^{1}$ (D) Paul D. Williams, ${ }^{1}$ (D) and Philip G. Gill ${ }^{2}$
}

\begin{abstract}
Atmospheric turbulence is a major hazard in the aviation industry and can cause injuries to passengers and crew. Understanding the physical and dynamical generation mechanisms of turbulence aids with the development of new forecasting algorithms and, therefore, reduces the impact that it has on the aviation industry. The scope of this paper is to review the dynamics of aviation turbulence, its response to climate change, and current forecasting methods at the cruising altitude of aircraft. Aviationaffecting turbulence comes from three main sources: vertical wind shear instabilities, convection, and mountain waves. Understanding these features helps researchers to develop better turbulence diagnostics. Recent research suggests that turbulence will increase in frequency and strength with climate change, and therefore, turbulence forecasting may become more important in the future. The current methods of forecasting are unable to predict every turbulence event, and research is ongoing to find the best solution to this problem by combining turbulence predictors and using ensemble forecasts to increase skill. The skill of operational turbulence forecasts has increased steadily over recent decades, mirroring improvements in our understanding. However, more work is needed-ideally in collaboration with the aviation industry-to improve observations and increase forecast skill, to help maintain and enhance aviation safety standards in the future.
\end{abstract}

\section{Introduction}

Atmospheric turbulence is a major aviation hazard, causing damage to aircraft and injury to passengers and crew. Turbulence is part of the chaotic atmosphere, and the chaotic nature poses a great challenge in understanding and forecasting turbulence. Aviation turbulence is incompletely understood and difficult to forecast, making it a significant hazard. The USA National Transportation Safety Board (NTSB) records the average number of

\footnotetext{
1 Department of Meteorology, University of Reading, Earley Gate, Reading RG6 6BB, UK. E-mail: luke.storer@pgr.reading.ac.uk

2 Met Office, FitzRoy Road, Exeter EX1 3PB, UK.
}

air-carrier-related injuries as 58 per year (FAA 2017b). However, Sharman et al. (2006) suggest that this number is an underestimate, as not all injuries are reported. They state that in the period 1980-2008, there were 234 turbulence accidents, resulting in 298 serious injuries and three fatalities on United States operated air carriers. 184 of the serious injuries involved flight attendants and 114 involved passengers (FAA 2017b). These turbulence injuries will come at a cost to the airlines in two ways: (1) through compensation being paid, which amounts to over $\$ 10$ million per year, and (2) through lost working days by injured cabin crew, which is over 7000 days per year (Sharman and Lane 2016). Although most of the flight is spent at the cruise phase (around $33,000-39,000 \mathrm{ft}$ ), this is also the most vulnerable part of the flight as passengers and crew are unbuckled, so encountering any turbulence would be more likely to result in injury. As a result, most incidents occur above $10,000 \mathrm{ft}$ (Sharman et al. 2006).

Kauffmann (2002) analysed, in detail, the impact that turbulence has on the aviation industry. He presents figures from the USA Federal Aviation Administration (FAA), who state that there were 342 reports of turbulence affecting flights on major air carriers over the period 1981-1997, with three fatalities, 80 serious injuries, and 769 minor injuries. These figures are similar to those of Sharman et al. (2006) and, again, may underestimate the real statistics of turbulence injuries. These values could also be higher in the future, as climate change is likely to increase the frequency of turbulence around the world, particularly in the mid-latitudes (Williams and Joshi 2013; Williams 2017; Storer et al. 2017). The cost of turbulence to the aviation industry is significant and comes from many sources, one of which is preventing aircraft from flying on the 
optimum route. This cost is as much as $\$ 16$ million a year, as it is estimated that $5 \%$ of flights are forced to fly non-optimal routes (Search Technology 2000). More importantly, it is also suggested that $15 \%$ of the diversions could have been avoided with improved turbulence detection. One form of turbulence detection could be using LIght Detection And Ranging (LIDAR) technology on the front of an aircraft. The current RADAR technology used by aircraft is unable to detect turbulence unless hydrometeors are present, whereas for clear-air turbulence, they are absent. However, LIDAR technology is able to sense clearair turbulence using non-hydrometeor particles. This technology could warn pilots of turbulence ahead, enabling them to divert or put on the seatbelt sign, so passengers and crew are aware of the upcoming danger. At the moment, however, Kauffmann (2002) calculates that LIDAR technology costs more to install than the saving would be, and therefore, rolling it out is not worth the investment. Satellites can be used to avoid some kinds of turbulence, particularly turbulence associated with convection (Mecikalski et al. 2007; Francis and Batstone 2013). There is also the potential for the new generation of satellites (e.g., GOES-16) with higher spatial and temporal resolutions to improve the avoidance of turbulence. This improvement could come from better identification of deep convection and the ability to resolve gravity waves that would otherwise be invisible to the older generation GOES satellites (Wimmers et al. 2018; Nunez 2018).

Forecasting turbulence is another possibility to mitigate injuries and damage. Turbulent eddies in the atmosphere occur on scales ranging from the planetary scale down to millimeters, but only eddies of approximately $100 \mathrm{~m}$ in size impact aviation (Sharman et al. 2006). This is a scale that is not explicitly simulated in forecasts, because the numerical models have resolutions too coarse to resolve the individual eddies. Therefore, turbulence diagnostics are used. These diagnostics generally work on the principle that the energy associated with turbulence on aviation-affecting scales cascades down from the larger scales that can be explicitly resolved by numerical models.

The different kinds of turbulence that impact aviation are outlined in Fig. 1. Vertical wind shear instabilities, mountain waves, and convection are the three main sources that we consider in this study. Turbulence in and near clouds can also cause injuries to passengers and crew, but can easily be detected visually by pilots and using on-board RADAR. Boundary-layer turbulence is not considered here, because it influences only a small portion of the flight after take-off and before landing.

This review paper examines the current understanding of the different sources of aviation turbulence (Sect. 2), how turbulence might change in the future because of climate change (Sect. 3), and the current methods of turbulence forecasting (Sect. 4). The paper concludes with a summary and discussion (Sect. 5).

\section{Turbulence Sources}

\subsection{Clear-Air Turbulence}

Clear-air turbulence (CAT) is defined as highaltitude aircraft bumpiness in regions devoid of significant cloudiness and away from thunderstorm activity (Chambers 1955). Far from mountains, CAT is generally accepted to result from shear instabilities. Wind shear is, therefore, a major source of CAT and is one of the best understood sources. Figure 1 indicates this type of turbulence and its association with the jet stream. To understand why shear causes turbulence, we must define the Richardson number:

$$
R i=\frac{N^{2}}{(\partial U / \partial z)^{2}}=\frac{(g / \theta)(\partial \theta / \partial z)}{(\partial U / \partial z)^{2}},
$$

where $N^{2}$ is the Brunt-Väisälä frequency squared, $U$ is horizontal wind speed, $z$ is altitude, $g$ is gravitational acceleration, and $\theta$ is potential temperature. The Richardson number is a nondimensional number with the numerator representing the stratification and the denominator representing the vertical wind shear. It follows from theoretical considerations that instability occurs when $R i<0.25$, so instability is favoured by large vertical wind shear (denominator) and weak stratification (numerator). In computational calculations using gridded data, numerical models rarely reach $R i=0.25$ due to the coarse resolutions, and therefore, thresholds of turbulence are model specific. To overcome this, Williams (2017) and 


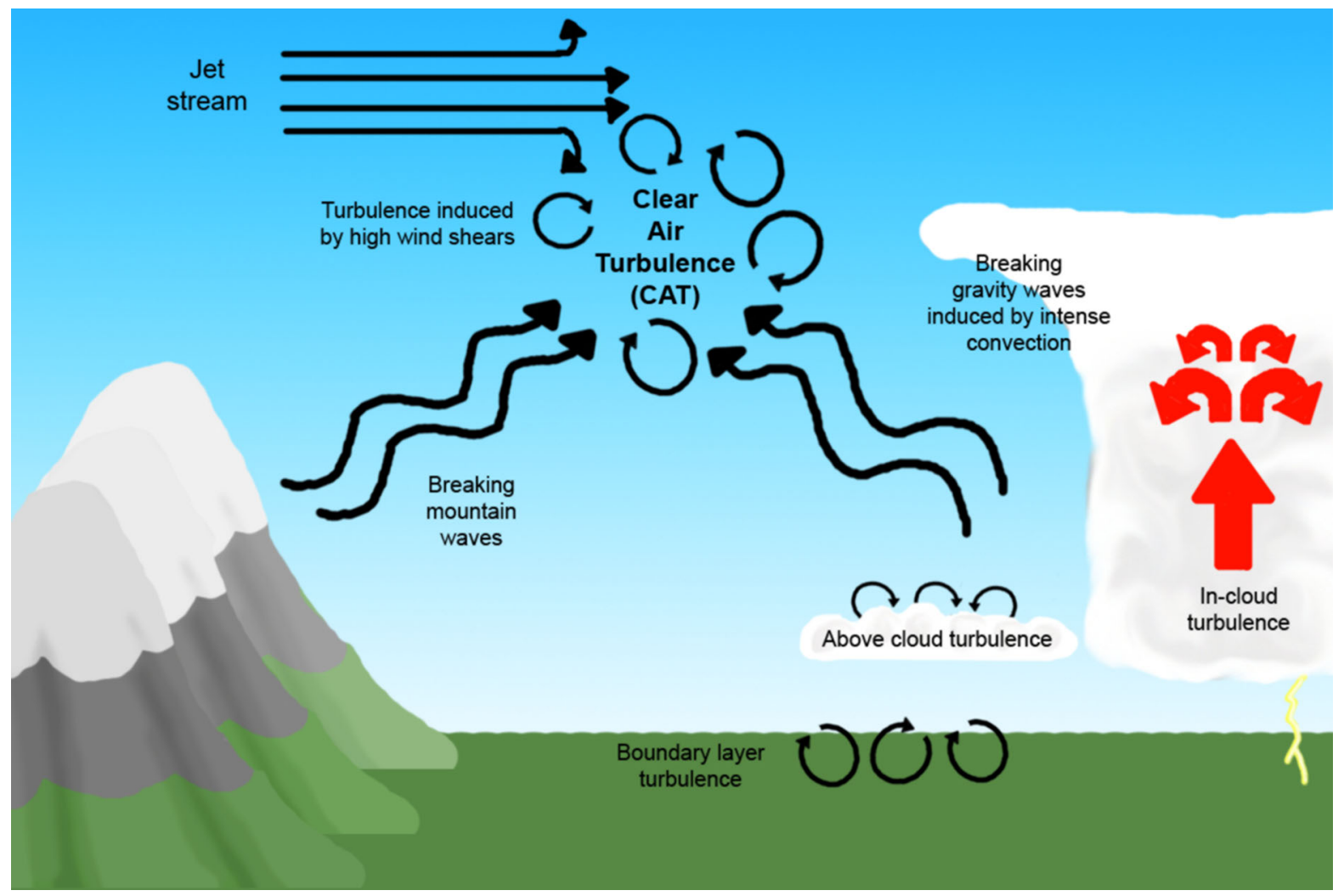

Figure 1

Plot of the main sources of turbulence that impact aviation: shear turbulence caused by high wind shear, breaking gravity waves induced by intense convection, and breaking mountain waves. From Marlton (2016)

Storer et al. (2017) chose thresholds based on the distribution of turbulence in the atmosphere. For example, they assume that severe turbulence is found in $0.01 \%$ of the atmosphere, and therefore, they take the top $0.01 \%$ (99.9-100\%) of the probability distribution to be severe turbulence. Therefore, each threshold is specific to each model and resolution.

It is possible for turbulence to be produced when the environmental Richardson number is much larger than the theoretical critical value, if a local effect reduces the Richardson number locally. For example, gravity waves can cause CAT by reducing the Richardson number $(R i)$ locally in an environment that would not normally produce turbulence, initiating the Kelvin-Helmholtz shear instability and leading ultimately to overturning and breaking billows. The various sources of gravity waves are discussed by Williams et al. (2003, 2005, 2008). In particular, gravity waves can be produced by convection (as discussed in Sect. 2.2) and spontaneous loss of geostrophic balance as the flow evolves, as described by the Lighthill-Ford theory (Lighthill 1952; Ford 1994; Knox et al. 2008; McCann et al. 2012). There is a direct connection in certain circumstances that links deformation to the generation of inertia-gravity waves (Knox et al. 2008). In some cases, this could explain the success of deformation-based CAT diagnostics such as Ellrod and Knapp (1992) TI1 and TI2 (Knox 1997).

It is also possible for the environmental Richardson number to be reduced on a much larger scale, in regions of the atmosphere with particularly strong wind shear such as the jet streams. Strong vertical wind shears around the jet stream increase the denominator in Eq. (1) which, therefore, decreases the Richardson number until it reaches a critical value and turbulence is produced. Therefore, understanding the behaviour of the jet stream will help researchers 
and forecasters to understand how CAT may change. This is one of the reasons for the success in forecasting turbulence of CAT diagnostics containing vertical wind shear [e.g., Colson-Panofsky index (Colson and Panofsky 1965), TI1, TI2 (Ellrod and Knapp 1992)].

Kim et al. (2016) studied the impact that the North Atlantic Oscillation (NAO) has on aviation turbulence. The NAO is a measure of the relative strength of the Icelandic low and the Azores high. The positive NAO phase implies a stronger than normal Icelandic low and Azores high, so there is a strong pressure difference between the two. In the negative NAO phase, the opposite is true and the pressure difference is weaker. In the positive NAO phase, we see a stronger jet stream and a more northerly path, whereas the negative NAO phase is associated with a weaker jet stream and a more southerly path. This change to the jet stream, therefore, has an impact on turbulence for transAtlantic flights. Kim et al. (2016) used wind-optimal routes to find the fastest possible flight path between London (LHR) and New York (JFK). The study found that eastbound flights fly more frequently through regions of CAT than westbound flights, and, therefore, experience more turbulence in both the positive NAO phase and the negative NAO phase. The reason for this is that eastbound flights utilise the jet stream more to benefit from strong tailwinds, so the wind-optimal routes would fly in stronger vertical shear regions more for eastbound flights than westbound flights. Westbound wind-optimal routes avoid the strong headwinds of the jet stream, and would also avoid the stronger vertical shear associated with the jet stream and, therefore, encounter less turbulence.

According to Kim et al. (2016), in the positive NAO phase, westbound flights experience more moderate-or-greater (MOG) CAT than in the negative NAO phase, because some of the westbound flights detour northward to be on the cyclonic shear side of the northerly shifted jet stream, which is more susceptible to MOG turbulence. In contrast, eastbound flights in the negative NOA phase fly through the cyclonic shear side of the southerly shifted jet. Therefore, the study suggests that westbound flights are more prone to MOG CAT in the positive NAO phase, whereas eastbound flights are more prone to MOG CAT in the negative NAO phase. This information is important for flight planners, as for example in a positive NAO phase, an eastbound flight would fly on the anticyclonic shear side of the jet stream, still using the tailwind to reduce flight time. However, a westbound flight that would normally fly north to avoid the strong headwinds should fly south and avoid the cyclonic shear side of the jet stream, reducing flight time but also the chances of strong turbulence. Information such as this can be used to avoid the strongest turbulence, while still attempting to reduce flight times and, therefore, fuel consumption.

Another example of jet stream behaviour was studied by Trier et al. (2012), who discuss how moist convection influences the upper level jet. This topic has been studied by Trier and Sharman (2009) for warm Mesoscale Convective Systems (MCSs). Latent heat release perturbs an anticyclone, and this mechanism accounts for nearly all of the magnitude of the upper level jet. This is a similar mechanism found in a cold weather outbreak, so a mid-latitude cyclone (like the MCS) enhances the downstream anticyclone. The study suggests that, although not as dominant as MCSs, mid-latitude cyclones account for $30-50 \%$ of the strength of the southerly jet stream. Without the moist convection and the perturbation of the anticyclone, the wind shear, and therefore, resultant CAT would not be as strong. This is different to CIT, because it is the indirect effect of convection on the jet stream and the increased shear that causes turbulence. The other mechanism is associated with strong convection in the mid-latitude cyclone. With cloud tops below the flight level, the cloud tops generate gravity waves induced by the convection. This mechanism is discussed further in Sect. 2.2.

\subsection{Convective Turbulence}

Understanding the relationship between buoyancy and shear is very important in understanding where and why turbulence forms. Lane et al. (2012) explore our current understanding of near-cloud turbulence or Convectively Induced Turbulence (CIT). They explain that the FAA regulations at the time were 
not sufficient for avoiding severe turbulence. For example, guideline 5 states: "Do avoid by at least 20 miles (laterally) any thunderstorm identified as severe or giving an intense radar echo, especially under the anvil of a large cumulonimbus". Guideline 6 states: "Do clear the top of a known or suspected severe thunderstorm by at least $1000 \mathrm{ft}$ altitude for each 10 knots of wind speed at the cloud top".

A possible source of CIT is unstable upper tropospheric thunderstorm outflow, similar to that described in Trier and Sharman (2009). Those authors proposed a mechanism for turbulence formation after completing simulations using a convectionpermitting model. Their proposed mechanism is the formation of strong vertical wind shear in the outflow regions of Mesoscale Convective Systems (MCS), which we know reduces $R i$ and leads to KelvinHelmholtz instability, which is a well-known source of turbulence. In the simulations, they also found that strong vertical wind shear created regions of strong static instability. This was caused by differentially advecting equivalent potential temperature gradients, which were influenced by the adiabatic cooling in the convective updrafts.

The above static instabilities are different from the traditional CIT mechanisms that generally result from high-frequency gravity wave breaking (Lane et al. 2003; Lane and Sharman 2008) or from reductions in $R i$ as a result of propagating gravity waves (Sharman et al. 2012). Propagating gravity waves induced by convection are indicated as a source of turbulence in Fig. 1. Lane et al. (2003) studied the traditional mechanisms forming turbulence above deep convection, and found that gravity waves formed when the overshooting top returns back down. As these waves propagate up, the changes in vertical wind shear and buoyancy with height can change the wavelength of gravity waves and the tilt. The phase speed remains the same above the jet as within the jet based on linear theory, and the decreasing speed above the jet could reach the critical level (Lane et al. 2012). This is found when $U(z)-c=0$, where $U(z)$ is vertical wind shear and $c=\omega / k$, with $\omega$ being the wave frequency and $k$ being the horizontal wave number. Therefore, the gravity wave can break if wave frequency is low, or wind shear is high.
Since wind shear is an important part of the gravity wave breaking, the jet stream plays an important role. The smaller the jet width, the larger the wind shear, and therefore, the closer to the cloud top the gravity wave breaking would be. Lane et al. (2012) also showed turbulence can be found in cirrus bands (banding caused by thermal instabilities), and also ducted gravity waves that propagate far from the updraft, reducing the Richardson number and causing turbulence much farther away than the $20 \mathrm{~km}$ outlined in the guidelines. The new guidelines from FAA (2017a) no longer reference the acceptable height above the thunderstorm pilots can fly. Guideline 2 now states: “Don't attempt to fly under a thunderstorm even if you can see through to the other side. Turbulence and wind shear under the storm could be hazardous". Guideline 3 states "Don't attempt to fly under the anvil of a thunderstorm. There is a potential for severe and extreme clear-air turbulence". Guideline 14 states "Do avoid by at least 20 miles any thunderstorm identified as severe or giving an intense radar echo. This is especially true under the anvil of a large cumulonimbus".

\subsection{Mountain-Wave Turbulence}

Mountain-wave turbulence is similar to Convectively Induced Turbulence, as gravity waves produced by the terrain (instead of convection) propagate and then break when a critical vertical wind shear value is reached (Nastrom and Fritts 1992; Wurtele et al. 1996). This is also indicated in Fig. 1 and shows its similarity to CIT. A study by Epifanio and Qian (2008) used a high-resolution ensemble to study turbulence produced by breaking mountain waves and found that their results were consistent with the previous work by Fritts et al. (1994, 1996), suggesting that shear is an important factor in the breaking of gravity waves. Fritts et al. (1996) ran simulations to understand the turbulence mechanism in mountain waves, and found that the dominant source of instability, and therefore turbulence, was the wind shear. This came from the mean wind field, and the differential vertical advection of the mean shear by the wave field. Similar to convective turbulence, the vertical wind shear and its interaction with propagating gravity waves is an important 
mechanism in turbulence production. This understanding will help forecasters in the future.

Wolff and Sharman (2008) show that MOG turbulence is typically found where topographic heights are above $1.5 \mathrm{~km}$. They also analysed the low-level wind direction when mountain-wave turbulence is produced, and concluded that the wind direction must be within $30^{\circ}$ of the perpendicular to the mountain range orientation. For north America, this makes the Rocky Mountains a prime location for MOG MWT, as the mountain range is oriented northsouth and frequently experiences westerly low-level flow with mountain heights above $1.5 \mathrm{~km}$. Greenland is also an area with high mountain ranges with the potential to cause turbulence for trans-Atlantic flights.

\section{Climatology and Response to Climate Change}

Jaeger and Sprenger (2007) used reanalysis data to understand upper tropospheric clear-air turbulence in the Northern Hemisphere, because of its role in stratosphere-troposphere exchange (Shapiro 1976, 1978, 1980). The authors create a climatology of the Ellrod and Knapp (1992) index (TI1), BruntVäisälä frequency squared $\left(\mathrm{N}^{2}\right)$, Richardson number $(R i)$, and potential vorticity (PV). Negative potential vorticity is a turbulence predictor as it is related to isentropic inertial instability. The study found that TI1 is largest north of the jet stream, and KelvinHelmholtz instability indicated by $R i$ is near the jets, which is what we would expect with larger wind shear in that region. Symmetric instability is most frequent south of the jets, and is particularly associated with anticyclonic jets. Hydrostatic instability is only slightly dependent on the jet position, and is most common over land where convection and gravity wave activity are most prevalent (mountain wave and deep convection gravity waves). The study also showed that winter (DJF) has the highest turbulence frequency, which follows the understanding that the jet stream is stronger in winter. The study also found long-term trends in the frequency of diagnosed turbulence over the reanalysis period. Figure 2 shows that over the reanalysis period, there is an increasing trend of turbulence in the northern
Hemisphere. They were also able to relate inter-annual variability to the North Atlantic Oscillation (NAO) and Pacific/North American flow, which we know from Sect. 2.1 influences CAT.

We know that the climate system is changing due to anthropogenic forcing, and these changes may have an impact on turbulence in the future. Collins et al. (2013) showed that the changes in temperature are not uniform around the world. Importantly for turbulence, the upper troposphere and lower stratosphere respond differently to anthropogenic forcing. The tropical upper troposphere is predicted to warm faster than the tropical surface, due to an increase in latent heat release. Latent heat is released during convection, and in a warmer climate the atmosphere can hold more moisture, and as a result more convection and subsequent latent heat release will warm the troposphere. The lower stratosphere, however, will cool with the increasing greenhouse gases (Fels et al. 1980). This cooling is related to changes in infrared radiation.

The upper tropospheric and lower stratospheric changes discussed above lead to an increase in the equator-to-pole temperature gradient at flight cruising levels, as shown in Fig. 3. Particularly in the RCP8.5 simulation (right), where greenhouse gas emissions are highest, we see the warming in the tropics, and the cooling at the poles, increasing the equator-topole temperature gradient. This increase in meridional temperature gradient will induce a thermal wind response, resulting in an increase in vertical wind shear and, therefore, turbulence in the mid-latitudes. These changes to the jet stream are shown in Fig. 4, which is taken from Delcambre et al. (2013). The changes to the jet stream are predominant in the midlatitudes and at airline cruise altitudes, making their impact the largest in the busiest flight regions around the world. In addition to modifying turbulence, the increased wind speeds are also expected to modify flight times (Williams 2016). Another impact of anthropogenic forcing is the 20th-century release of chlorofluorocarbons (CFCs), which destroy atmospheric ozone $\left(\mathrm{O}_{3}\right)$. The loss of ozone reduces the lower stratospheric temperature, further increasing the equator-to-pole temperature gradient. This effect enhances the predicted change arising from carbon dioxide. 

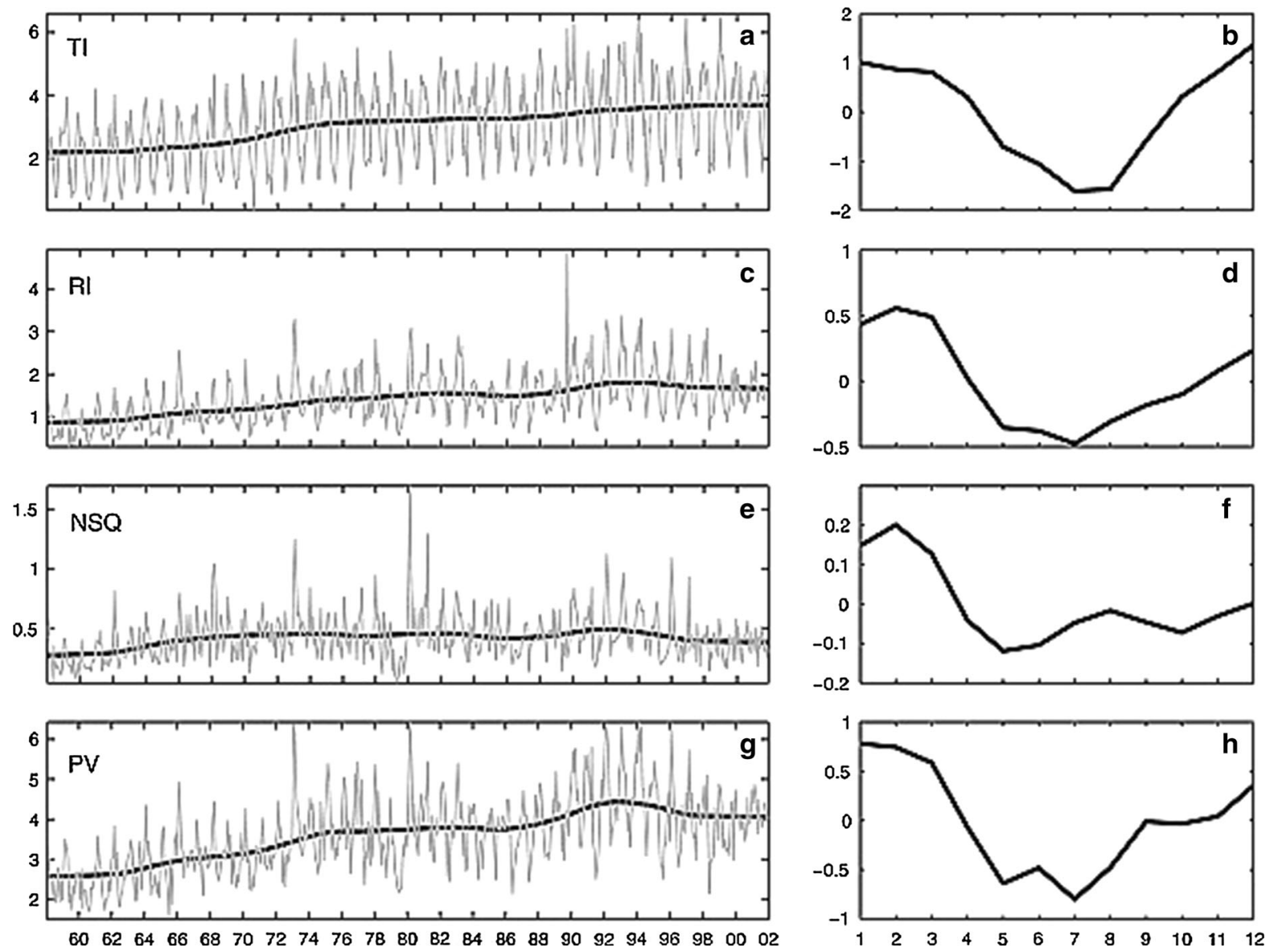

Figure 2

(Left) TI, Ri, $\mathrm{N}^{2}$, and PV (from top to bottom) frequency time series (grey lines) and nonlinear trend estimates from STL analysis (bold black line) for the North Atlantic sector from $90^{\circ} \mathrm{W}-10^{\circ} \mathrm{E}$ and $30^{\circ}-70^{\circ} \mathrm{N}$ in the tropopause region (\%). (Right) Mean seasonal cycle component of the turbulence indicators from STL decomposition $(\Delta \%)$. All panels are for the time period 1958-2001. Note the different scales. From Jaeger and Sprenger (2007)

Several studies have reported that climate change will act to increase clear-air turbulence in the future, according to climate model simulations (Williams and Joshi 2013; Williams 2017; Storer et al. 2017). The first study to look at this (Williams and Joshi 2013) focused on north Atlantic moderate-or-greater turbulence and showed that it would increase in frequency with climate change by around 40-170\%. Williams (2017) then furthered the study to see how climate change might influence turbulence in five strength categories from light to severe, finding that all would increase in frequency with climate change. Storer et al. (2017) then extended the work further to see how climate change will impact CAT globally, through all four seasons, and also at two flight levels in eight geographic regions. They found that CAT will increase globally in all four seasons. This is shown in Fig. 5, with the largest and most statistically significant increases confined to the mid-latitudes around the jet stream. Some regions locally will see increases of several hundred per cent for example at $200 \mathrm{hPa}(39,000 \mathrm{ft}$.) the north Atlantic will see an increase of $143.3 \%$ in moderate turbulence and $181.4 \%$ in severe turbulence. The study also showed that at $200 \mathrm{hPa}$ (1) in winter, severe CAT by 2050-2080 will be as common as moderate CAT in the control period, and (2) for a range of turbulence strengths from light to moderate-to-severe, 


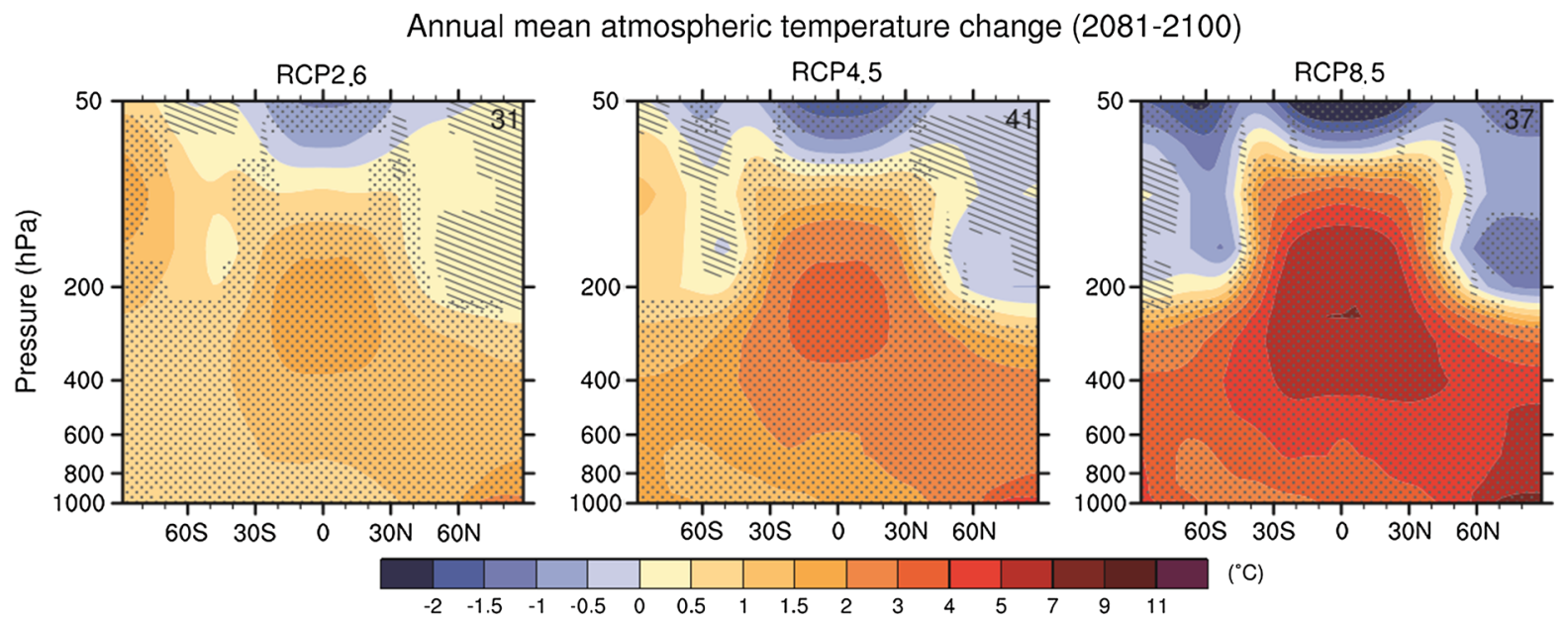

Figure 3

Modelled zonal-mean annual-mean ensemble-mean future temperature changes for climate change scenario RCP2.5 (left), RCP4.5 (middle), and RCP8.5 (right). Hatching indicates the regions where the ensemble-mean change is less than one standard deviation of internal variability. Stippling indicates regions where the ensemble-mean change is greater than two standard deviations of internal variability and where at least $90 \%$ of the models agree on the sign of the change. From Collins et al. (2013). Available under https://creativecommons.org/licenses/by/3.0/

summertime CAT by 2050-2080 will be as common as wintertime CAT in the control period. Aircraft manufacturers and forecasters need to be prepared to prevent an increase in damage to aircraft and injuries to passengers and crew.

Currently, there is a gap in the literature looking at the response of Convectively Induced Turbulence and Mountain-Wave Turbulence to climate change. However, we know that deep convection can produce turbulence, and therefore, it is likely that CIT would increase if convection was increased. Price and Rind (1994) showed an increase of 5-6\% of global lightning activity with every $1{ }^{\circ} \mathrm{C}$ of global warming. Lightning activity has been used to characterise turbulence events (Gill and Stirling 2013; Meneguz et al. 2016), and therefore, if we see an increase in lightning, we would expect to see an increase in convection and possibly an increase in CIT as a result. Price and Rind (1994) show that lightning activity and convection will increase particularly around the tropics, which is the area where CAT is not expected to increase (Fig. 5). Therefore, combining CAT and CIT, we would see a global increase in all aviation turbulence. This trend of increasing lightning with climate change is supported by Reeve and Toumi (1999) who show an increase in lightning activity of $40 \%$ for every $1 \mathrm{~K}$ of average land wet- bulb temperature. It could be possible to study the change in CIT to climate change. Convective precipitation accumulation was used by Gill and Stirling (2013) as a convective indicator for turbulence forecasts, and therefore, assessing the changes of this quantity in climate models could indicate how climate change might impact CIT.

\section{Forecasting}

Currently, the World Area Forecast Centres (WAFCs) in London (Met Office) and Washington (NOAA) produce operational turbulence forecasts for aviation. This includes a $t+24 \mathrm{~h}$ significant weather (SIGWX) chart four times a day (0000, 0006, 0012, 0018 UTC) which displays multiple aviation hazards including icing, CAT, as well as the location of convective cloud. The WAFCs also produce a gridded turbulence forecast four times a day at five pressure levels with a lead time $t+6 \mathrm{~h}$ to $t+36 \mathrm{~h}$ (Gill 2014).

\subsection{Clear-Air Turbulence}

Using diagnostics to forecast clear-air turbulence allows flight planners to avoid turbulent regions. Fahey (1993) showed that strategic planning can lead 

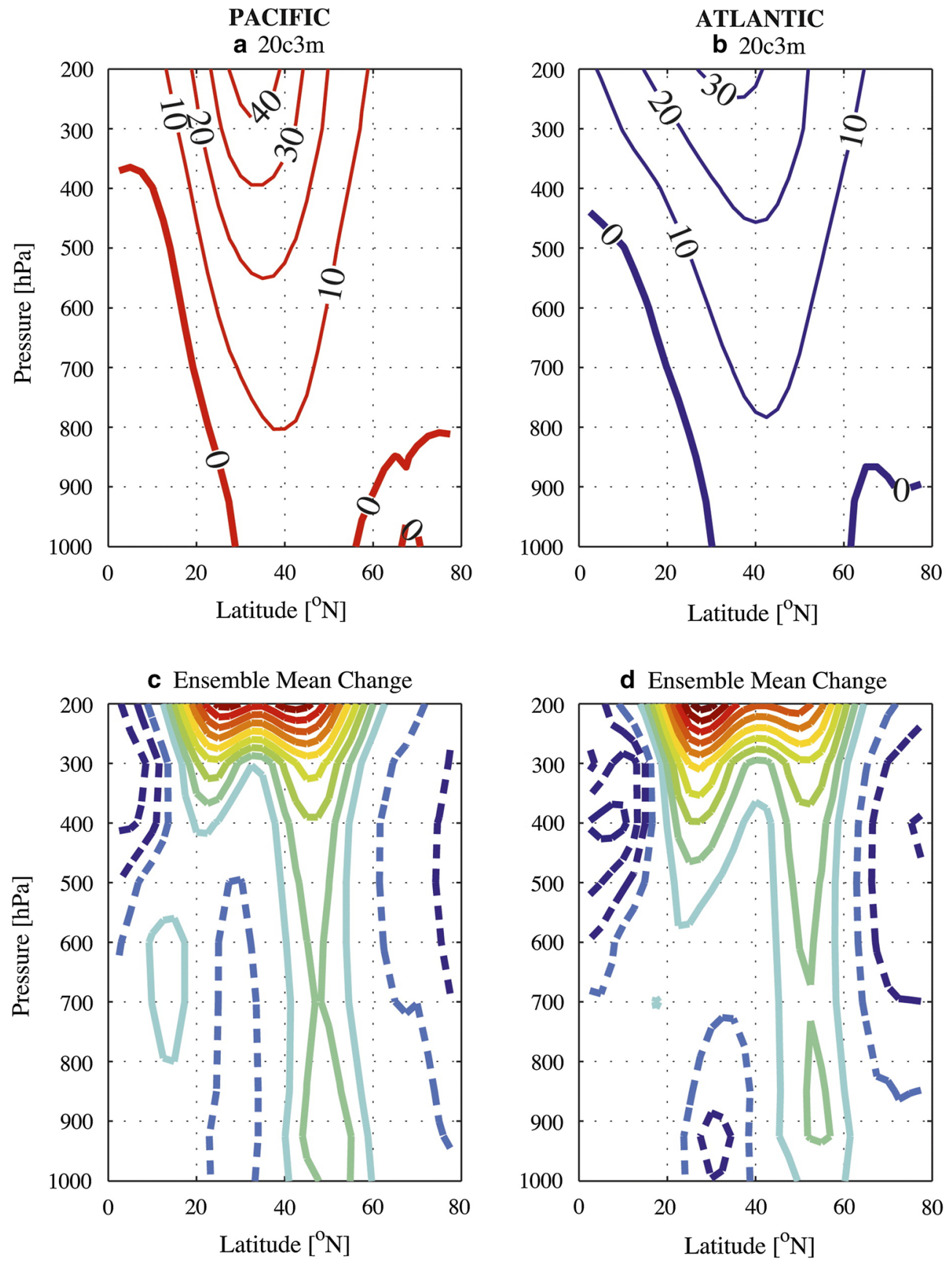

Figure 4

Modelled zonal-mean annual-mean ensemble-mean future zonal wind changes. The zonal mean is taken over the Pacific (left) and Atlantic (right). The upper row shows a control period contoured every $10 \mathrm{~m} \mathrm{~s}^{-1}$ and the lower row shows the future change contoured every $0.25 \mathrm{~m} \mathrm{~s}^{-1}$. From Delcambre et al. (2013). (CAmerican Meteorological Society. Used with permission

to not only a reduction in injuries, but also costs. The use of diagnostics is also the only way to operationally forecast turbulence, as the turbulent eddies that affect aviation are smaller than the resolution of global atmospheric models. Turbulence predictors that have a deformation term are particularly good at 

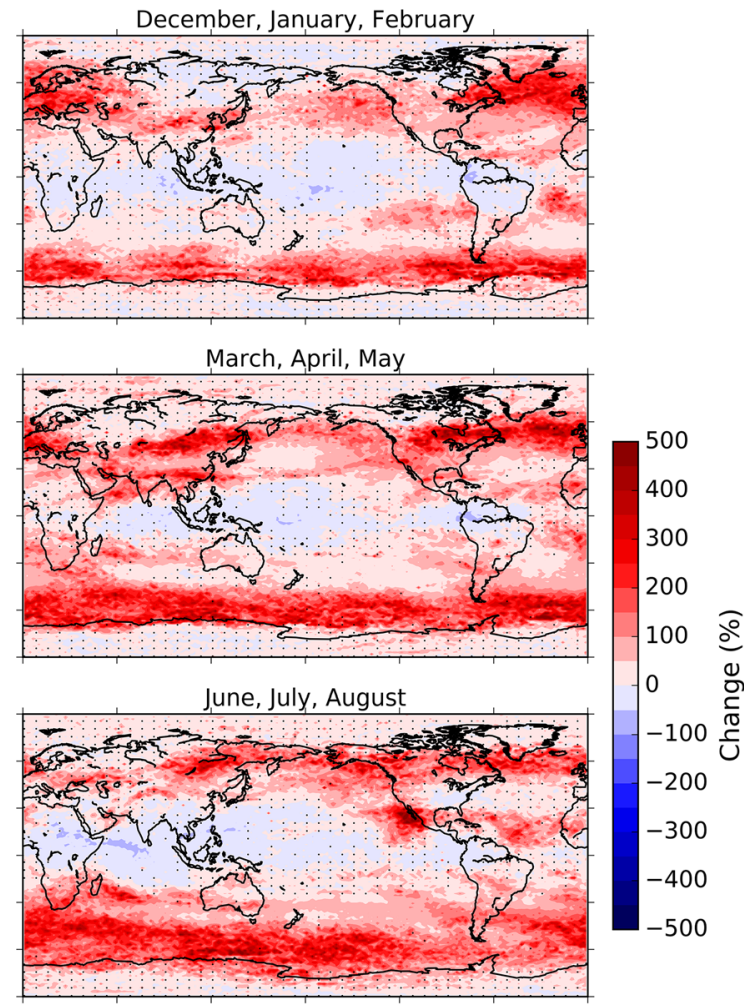

September, October, November

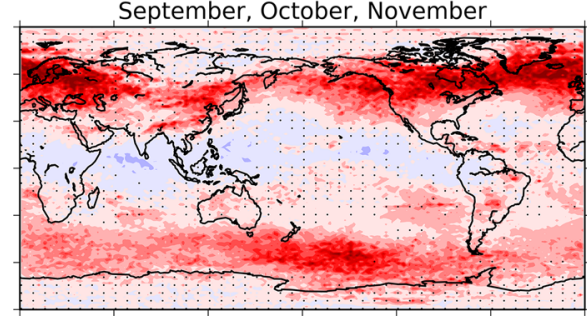

Figure 5

Maps of the average percentage change in the amount of moderate CAT from pre-industrial times (picontrol) to the period 2050-2080 (RCP8.5) at $200 \mathrm{hPa}$ in each season. The average is taken over 20 CAT diagnostics, which are equally weighted. Stippling indicates regions where the average percentage change is not significantly different from zero at the $90 \%$ level according to the one-sample, two-tailed $t$ test. From Storer et al. (2017)

forecasting CAT. Knox et al. (2008) tried to understand the previous work that linked deformation to Kelvin-Helmholtz instabilities. This included frontogenesis that could initiate Kelvin-Helmholtz instabilities, or mesoscale waves that would then break down and form turbulence (Mancuso and Endlich 1966). They found that neither could fully explain the relationship between deformation and turbulence, so instead found a link between deformation and inertia-gravity wave generation via the Lighthill-Ford theory. In certain atmospheric environments close to shear instability (low Richardson number), gravity waves emitted by imbalance destabilize the atmosphere, locally reducing $\mathrm{Ri}$ to below the critical value of 0.25 and leading to Kelvin-Helmholtz instabilities, generating waves which break down and form turbulence (Miles and Howard 1964; Dutton and Panofsky 1970). This explains the success of empirical diagnostics such as Turbulence Index 1 (TI1) from Ellrod and Knapp (1992):

$$
\begin{aligned}
\mathrm{TI} 1= & {\left[\left(\frac{\partial u}{\partial x}-\frac{\partial v}{\partial y}\right)^{2}+\left(\frac{\partial v}{\partial x}+\frac{\partial u}{\partial y}\right)^{2}\right]^{1 / 2} } \\
& \times\left[\left(\frac{\partial u}{\partial z}\right)^{2}+\left(\frac{\partial v}{\partial z}\right)^{2}\right]^{1 / 2}
\end{aligned}
$$

where $u$ is the eastward wind speed and $v$ is the westward wind speed. TI1 found in equation (2) is one of the best shear turbulence forecast diagnostics, and has been found to forecast up to $75 \%$ of all CAT cases. This is why a deterministic TI1 forecast is routinely used by the WAFCs.

McCann et al. (2012) furthered the work by Knox et al. (2008) to try and improve the forecast based on spontaneous imbalance. They made an algorithm that could be used operationally by improving the forecast below FL200 (which was a problem with the current diagnostics). The apparent high bias in turbulent kinetic energy dissipation above the tropopause is reduced by including the turbulent kinetic energy production from the environment and the locally produced turbulent kinetic energy. McCann et al. (2012) also converted the turbulent kinetic energy into an eddy dissipation rate (EDR), which is now a standard measure of turbulence in the atmosphere as it does not depend on aircraft size.

There are many turbulence diagnostics, each with its own its strengths and weaknesses. All forecast CAT and are unable to forecast convective turbulence or mountain-wave turbulence. Since each individual diagnostic is unable to forecast every CAT event, Sharman et al. (2006) generated the Graphical Turbulence Guidance (GTG) system for forecasting turbulence. They selected multiple turbulence 
diagnostics and then used PIlot REPorts (PIREPS) to understand the diagnostics' performances. A weighting system can then be added depending on the skill of each diagnostic to produce the best overall forecast possible. The study showed that this was an improvement over the single turbulence diagnostic, and is, therefore, worth doing. Over the years, this forecast has been improved, and more recently, a mountainwave turbulence predictor has been added to the GTG system. At the moment CIT is not forecast by the GTG system, but it has been shown that it is a useful addition (Gill and Stirling 2013).

\subsection{Convective Turbulence}

Convection is one of the main turbulence sources. It is not yet forecast using numerical models operationally, but, instead, forecasters manually put the location of convective clouds on the significant weather (SIGWX) charts used by pilots and flight planners. Gill and Stirling (2013) showed that using a convective diagnostic from numerical weather prediction output can forecast many convective turbulence events. Therefore, combining the shear turbulence predictors and the convective predictors (similar to GTG) offers the promise to greatly improve the forecast skill. The convective indicators used in the study included convective precipitation rate, convective precipitation accumulation, and Convective Available Potential Energy (CAPE). Gill and Stirling (2013) concluded that it is possible to improve turbulence forecasts by not only combining different predictors for the same turbulence source (e.g., TI1, Brown index, etc.) but also combining predictors for different turbulence sources as well (e.g., clear-air turbulence and convective turbulence). They suggest that more work is needed in this area, but there is the potential to greatly increase the forecast skill by adding in these extra turbulence diagnostics and forecasting a greater proportion of turbulence events.

\subsection{Mountain-Wave Turbulence}

An algorithm for forecasting mountain-wave turbulence was described by Turner (1999). Mountain waves are a special case of gravity waves and they are smaller than the numerical resolution of the models, so the wave stress has to be parameterised. To do this, the surface winds and stability are used to work out a wind stress, and then, the wind stress is used to work out the vertical profile. The wind stress is computed for every grid point, taking into account the abruptness of orography (as that is the location of the mountains). The surface stress is passed upwards from the surface (unless a hydraulic jump, critical level, or saturation stress is diagnosed), and therefore, less stress is transferred to the next level. Above the maximum point that gravity wave stress can be sustained, the waves break and thus turbulence forms, so the models can use the wave stress at each model level to calculate the location and height at which the gravity wave stress is too high. This is, therefore, the turbulence location in the model. For mountain-wave formation, the higher the gravity wave propagates, the more likely it is to break. This is because the maximum gravity wave stress which the atmosphere can hold decreases with increased wind shear and lower air density. Mountain-wave turbulence is found to be associated most strongly with the mid-latitude westerlies and mountains perpendicular to the flow.

The new GTG3 system includes mountain-wave turbulence diagnostics alongside the typical CAT diagnostics (Sharman and Pearson 2017). These authors have also used a different approach to forecasting MWT and use a combination of lowlevel wind combined with CAT diagnostics. The authors produced 14 new MWT diagnostics, which showed an increased forecast skill in MWT prone areas, supporting their use in the new GTG system.

\subsection{Ensemble Forecasting}

One of the main problems with the turbulence forecasting methods outlined in Sects. 4.1, 4.2, and 4.3 is that they do not convey uncertainty. To resolve this issue, Gill and Buchanan (2014) and Buchanan (2016) trialled the use of ensemble forecasting for aviation turbulence. An ensemble is a collection of forecast runs, each of which is considered to be equally likely. Using an ensemble, the uncertainty in the forecast can be found. In these studies, the Met Office Global and Regional Ensemble Prediction System (MOGREPS) was used, which was made operational in 2008 (Bowler et al. 2008). Multiple 
turbulence predictors were considered, including the Dutton (1980) index, the Ellrod and Knapp (1992) indices, the Brown (1973) index, the Lunnon index (Roach and Dixon 1970), the Richardson number, and two convective predictors. Using the Derived Equivalent Vertical Gust (DEVG) as a truth in the verification, the studies found that using the ensemble forecast, they increased the forecast skill for most of the turbulence diagnostics.

The studies by Gill and Buchanan (2014) and Buchanan (2016) then combined the predictors in a manner similar to Sharman et al. (2006), using an iterative scheme to maximise the forecast skill. Again, the studies showed that the ensemble forecast was more skillful than a single model deterministic forecast. A probabilistic forecast would also be more useful for pilots and flight planners, as understanding the uncertainty of the forecast can help them to make the best decision possible to maintain safety of passengers and crew, while still flying the optimum routes and reducing flight times and fuel consumption. Further work is needed in ensemble forecasting before it can be used operationally, such as studying whether multimodel ensembles can improve the forecast. In addition, more research is needed to include a mountain-wave turbulence predictor alongside the convective and shear turbulence predictors. However, it is clear that ensembles can be beneficial and should eventually be used operationally in the future.

\subsection{Forecast Verification}

Turbulence forecast verification is difficult, because objective verification data sets are limited. Some previous studies resolved this issue using PIREPs (Kim and Chun 2011; Schwartz 1996) to identify regions of turbulence based on a semi-quantitative scale from light to extreme, but these can be unreliable (Kane et al. 1998). PIREPs are subjective, in the sense that a more experienced pilot may catagorise an event as moderate, but an inexperienced pilot may record it as severe. In addition, PIREPs are aircraft-dependent, so a smaller aircraft will experience stronger turbulence than a larger aircraft in the same volume of air. PIREPs also have poor spatial reliability as they tend to be located in turbulence, so null turbulence events are rarely recorded (Kane et al. 1998).
To avoid the above problems, there are two main aircraft-independent measures, which are the Eddy Dissipation Rate (EDR) and the Derived Equivalent Vertical Gust (DEVG). The measures are calculated using high-resolution automated aircraft data, available at $4 \mathrm{~s}$ intervals. The EDR is calculated following Haverdings and Chan (2010) using:

$$
\operatorname{EDR}=\frac{\sigma_{w}}{\sqrt{1.05 V_{a}^{\frac{2}{3}}\left(\omega_{1}^{-\frac{2}{3}}-\omega_{2}^{-\frac{2}{3}}\right)}},
$$

where $\sigma_{w}$ is the running mean of the vertical wind shear over a 10 second time window, $V_{a}$ is the true airspeed, and $\omega_{1}$ and $\omega_{2}$ are cut-off frequencies set at 0.1 and $2 \mathrm{~Hz}$, respectively. The DEVG (Tenenbaum 1991; Gill 2014, 2016; Kim et al. 2017) is calculated following Truscott (2000) using:

$$
\mathrm{DEVG}=\frac{A m|\Delta n|}{V},
$$

where $|\Delta n|$ is the peak modulus value of the deviation of the aircraft acceleration from $1 g$ in units of $g, m$ is the total mass of the aircraft (metric tonnes), $V$ is the calibrated airspeed at the time of the observation (knots), and $A$ is an aircraft-specific parameter that varies with flight conditions and can be calculated using the following:

$$
A=\bar{A}+c_{4}\left(\bar{A}-c_{5}\right)\left(\frac{m}{\bar{m}}-1\right)
$$

and:

$$
\bar{A}=c_{1}+\frac{c_{2}}{c_{3}+H(k f t)},
$$

where $H$ is the altitude (thousands of feet), $\bar{m}$ is the reference mass of the aircraft (metric tonnes), and parameters $c_{1}-c_{5}$ depend on the aircraft's flight profile as outlined by Truscott (2000).

Unlike PIREPs, EDR and DEVG are aircraftindependent, and therefore, all observations from multiple different aircraft can be combined to create a consistent observational database. Also unlike PIREPs, EDR and DEVG report all results including null reports. Because it is automated, the entire flight is recorded, and therefore, the only limit in coverage is the location the aircraft fly. Therefore, if every commercial aircraft had this capability, then all 
turbulence events could be recorded, and forecast verification improved. There are limitations to using the DEVG data set, as aircraft manoeuvres and active control techniques can enhance or dampen vertical accelerations of aircraft, leading to over- or underrepresentation of the vertical gusts (WMO 2003). However, despite these limitations, using an aircraftindependent measure (such as EDR or DEVG) is preferable to pilot reports (PIREPs).

\section{Summary}

Atmospheric turbulence is a major aviation hazard and we do not yet fully understand it. As a result, it causes many injuries to passengers and crew all around the world, with millions of dollars lost due to aircraft damage, planes being in the wrong place from a diverted flight, loss of hours from cabin crew, and compensation. This study has reviewed how turbulence that affects aviation can come from three main sources. The first is shear turbulence and is mainly found around the jet stream. The second is Convectively Induced Turbulence (CIT), and this forms around deep convection. However, there are multiple mechanisms that produce turbulence from convection, one of which is similar to the mechanism for the third source of turbulence known as Mountain-Wave Turbulence, which occurs when orography perturbs the atmosphere and produces gravity waves that can lead to turbulence.

This study has also reviewed how climate change is expected to have a large impact on clear-air turbulence in the future, with several studies finding that CAT will increase with climate change, particularly around the mid-latitudes in all seasons.

This makes turbulence forecasting very important in the future, to maintain the safety of passengers and crew. Currently, only one turbulence index known as the Ellrod and Knapp (1992) Turbulence Index 1 (TI1) is used by the two World Area Forecast Centres (WAFCs), but others have been included in the Graphical Turbulence Guidance (GTG) forecast. GTG combines many indices but is not yet used fully operationally in the WAFCs. Ensemble forecasting has also been developed to improve the forecasts, as currently only a deterministic forecast is created and that does not show the uncertainty in the forecast. The use of next-generation satellites (e.g., GOES-16) could help to improve nowcasting of turbulence, because with higher spatial and temporal resolutions, convection and gravity waves are more clearly resolved, aiding avoidance on the short time scales.

We know that the current methods of aviation turbulence forecasting are imperfect, and not all turbulence events are predicted. Therefore, continuing research to improve the forecast systems should be a high priority in the future. In addition, the aviation industry must make sure that the aircraft of the future are up to the challenge. This is because turbulence is not the only aviation hazard, with take-off weight restrictions due to high temperatures or aircraft icing also major hazards that might change in the future. In addition, the airline industry's desire to choose the most time-effective route to reduce fuel consumption and costs may force some pilots to fly into more turbulence regions. By making sure that all these aspects are taken into account, new and better working processes can be developed to make sure that the impact aviation has on the climate, and the impact climate change may have on aviation, are both reduced. With the volume of air travel also expected to increase over time, resulting in more congested skies, the research conducted now is vital to making sure that the industry is prepared for the future.

\section{Acknowledgements}

L.N.S. acknowledges support through a Ph.D. studentship from the Natural Environment Research Council SCENARIO Doctoral Training Partnership (reference NE/L002566). P.D.W. acknowledges support through a University Research Fellowship from the Royal Society (reference UF130571). The authors would also like to thank Dr. Graeme Marlton for providing Fig. 1.

Open Access This article is distributed under the terms of the Creative Commons Attribution 4.0 International License (http:// creativecommons.org/licenses/by/4.0/), which permits unrestricted use, distribution, and reproduction in any medium, provided you give appropriate credit to the original author(s) and the source, provide a link to the Creative Commons license, and indicate if changes were made. 


\section{REFERENCES}

Bowler, N. E., Arribas, A., Mylne, K. R., Robertson, K. B., \& Beare, S. E. (2008). The MOGREPS short-range ensemble prediction system. Quarterly Journal of the Royal Meteorological Society, 134(632), 703-722.

Brown, R. (1973). New indices to locate clear-air turbulence. Meteorological Magazine, 102, 347-361.

Buchanan, P. (2016). Aviation turbulence ensemble techniques. In: Aviation turbulence, pp. 285-296. Springer.

Chambers, E. (1955). Clear air turbulence and civil jet operations. The Aeronautical Journal, 59(537), 613-628.

Collins, M., Knutti, R., Arblaster, J., Dufresne, J.-L., Fichefet, T., Friedlingstein, P., et al. (2013). Long-term climate change: projections, commitments and irreversibility. Cambridge: Cambridge University Press.

Colson, D., \& Panofsky, H. (1965). An index of clear air turbulence. Quarterly Journal of the Royal Meteorological Society, 91(390), 507-513.

Delcambre, S. C., Lorenz, D. J., Vimont, D. J., \& Martin, J. E. (2013). Diagnosing Northern Hemisphere jet portrayal in 17 CMIP3 global climate models: Twenty-first-century projections. Journal of Climate, 26(14), 4930-4946.

Dutton, M. (1980). Probability forecasts of clear-air turbulence based on numerical-model output. Meteorological Magazine, 109(1299), 293-306.

Dutton, J. A., \& Panofsky, H. A. (1970). Clear air turbulence: A mystery may be unfolding. Science, 167(3920), 937-944.

Ellrod, G. P., \& Knapp, D. I. (1992). An objective clear-air turbulence forecasting technique: Verification and operational use. Weather and Forecasting, 7(1), 150-165.

Epifanio, C. C., \& Qian, T. (2008). Wave-turbulence interactions in a breaking mountain wave. Journal of the Atmospheric Sciences, 65(10), 3139-3158.

FAA. (2017a). Air traffic plans and publications. https://www.faa. gov/air_traffic/publications. Accessed 09 Feb 2018.

FAA. (2017b). Turbulence: Staying safe. https://www.faa.gov/ travelers/fly_safe/turbulence/. Accessed 09 Feb 2018.

Fahey, T. H. (1993). Northwest airlines atmospheric hazards advisory and avoidance system. In: International conference on aviation weather systems, 5th, Vienna, VA, pp. 409-413.

Fels, S., Mahlman, J., Schwarzkopf, M., \& Sinclair, R. (1980). Stratospheric sensitivity to perturbations in ozone and carbon dioxide: Radiative and dynamical response. Journal of the Atmospheric Sciences, 37(10), 2265-2297.

Ford, R. (1994). Gravity wave radiation from vortex trains in rotating shallow water. Journal of Fluid Mechanics, 281, 81-118.

Francis, P. N., \& Batstone, C. (2013). Developing a satellite product to identify severe convective storms hazardous to aviation. Satellite Applications Technical Memo 11.

Fritts, D. C., Garten, J. F., \& Andreassen, Ø. (1996). Wave breaking and transition to turbulence in stratified shear flows. Journal of the Atmospheric Sciences, 53(8), 1057-1085.

Fritts, D. C., Isler, J. R., \& Andreassen, Ø. (1994). Gravity wave breaking in two and three dimensions: 2.Three-dimensional evolution and instability structure. Journal of Geophysical Research: Atmospheres, 99(D4), 8109-8123.

Gill, P. G. (2016). Aviation turbulence forecast verification. In: Aviation turbulence, pp. 261-283. Springer.
Gill, P. G. (2014). Objective verification of World Area Forecast Centre clear air turbulence forecasts. Meteorological Applications, 21(1), 3-11.

Gill, P. G., \& Buchanan, P. (2014). An ensemble based turbulence forecasting system. Meteorological Applications, 21(1), 12-19.

Gill, P. G., \& Stirling, A. J. (2013). Including convection in global turbulence forecasts. Meteorological Applications, 20(1), 107-114.

Haverdings, H., \& Chan, P. W. (2010). Quick access recorder data analysis software for windshear and turbulence studies. Journal of Aircraft, 47(4), 1443-1447.

Jaeger, E., \& Sprenger, M. (2007). A Northern Hemispheric climatology of indices for clear air turbulence in the tropopause region derived from ERA40 reanalysis data. Journal of Geophysical Research Atmospheres, 112(D20).

Kane, T., Brown, B., \& Bruintjes, R. (1998). Characteristics of pilot reports of icing. In: Preprints: 14th conference on probability and statistics, pp. 11-16.

Kauffmann, P. (2002). The business case for turbulence sensing systems in the US air transport sector. Journal of Air Transport Management, 8(2), 99-107.

Kim, J.-H., Chan, W. N., Sridhar, B., Sharman, R. D., Williams, P. D., \& Strahan, M. (2016). Impact of the North Atlantic Oscillation on transatlantic flight routes and clear-air turbulence. Journal of Applied Meteorology and Climatology, 55(3), 763-771.

Kim, J.-H., \& Chun, H.-Y. (2011). Statistics and possible sources of aviation turbulence over South Korea. Journal of Applied Meteorology and Climatology, 50(2), 311-324.

Kim, S.-H., Chun, H.-Y., \& Chan, P. W. (2017). Comparison of turbulence indicators obtained from in situ flight data. Journal of Applied Meteorology and Climatology, 56(6), 1609-1623.

Knox, J. A. (1997). Possible mechanisms of clear-air turbulence in strongly anticyclonic flows. Monthly Weather Review, 125(6), 1251-1259.

Knox, J. A., McCann, D. W., \& Williams, P. D. (2008). Application of the Lighthill-Ford theory of spontaneous imbalance to clear-air turbulence forecasting. Journal of the Atmospheric Sciences, 65(10), 3292-3304.

Lane, T. P., \& Sharman, R. D. (2008). Some influences of background flow conditions on the generation of turbulence due to gravity wave breaking above deep convection. Journal of Applied Meteorology and Climatology, 47(11), 2777-2796.

Lane, T. P., Sharman, R. D., Clark, T. L., \& Hsu, H.-M. (2003). An investigation of turbulence generation mechanisms above deep convection. Journal of the Atmospheric Sciences, 60(10), 1297-1321.

Lane, T. P., Sharman, R. D., Trier, S. B., Fovell, R. G., \& Williams, J. K. (2012). Recent advances in the understanding of near-cloud turbulence. Bulletin of the American Meteorological Society, 93(4), 499-515.

Lighthill, M. J. (1952). On sound generated aerodynamically. I. General theory. Proceedings of the Royal Society of London A: Mathematical Physical and Engineering Sciences, 211, 564-587.

Mancuso, R., \& Endlich, R. (1966). Clear air turbulence frequency as a function of wind shear and deformation. Monthly Weather Review, 94(9), 581-585.

Marlton, G. J. (2016). On the development, characterisation and applications of a balloon-borne atmospheric turbulence sensor. Ph.D. thesis, University of Reading. 
McCann, D. W., Knox, J. A., \& Williams, P. D. (2012). An improvement in clear-air turbulence forecasting based on spontaneous imbalance theory: The ULTURB algorithm. Meteorological Applications, 19(1), 71-78.

Mecikalski, J. R., Berendes, T. A., Feltz, W. F., Bedka, K. M., Bedka, S. T., Murray, J. J., et al. (2007). Aviation applications for satellite-based observations of cloud properties, convection initiation, in-flight icing, turbulence, and volcanic ash. Bulletin of the American Meteorological Society, 88(10), 1589-1607.

Meneguz, E., Wells, H., \& Turp, D. (2016). An automated system to quantify aircraft encounters with convectively induced turbulence over europe and the northeast atlantic. Journal of Applied Meteorology and Climatology, 55(5), 1077-1089.

Miles, J. W., \& Howard, L. N. (1964). Note on a heterogeneous shear flow. Journal of Fluid Mechanics, 20(2), 331-336.

Nastrom, G. D., \& Fritts, D. C. (1992). Sources of mesoscale variability of gravity waves. Part I: Topographic excitation. Journal of the Atmospheric Sciences, 49(2), 101-110.

Nunez, R. (2018). Integrating GOES-16 satellite into convective porosity determination at CWSU Houston. In Sixth aviation, range, and aerospace meteorology special symposium, Austin, TX: American Meteorological Society.

Price, C., \& Rind, D. (1994). Possible implications of global climate change on global lightning distributions and frequencies. Journal of Geophysical Research Atmospheres, 99(D5), 10823-10831.

Reeve, N., \& Toumi, R. (1999). Lightning activity as an indicator of climate change. Quarterly Journal of the Royal Meteorological Society, 125(555), 893-903.

Roach, W., \& Dixon, R. (1970). A note on the paper on the influence of synoptic development on the production of high level turbulence. Quarterly Journal of the Royal Meteorological Society, 96(410), 758-760.

Schwartz, B. (1996). The quantitative use of pireps in developing aviation weather guidance products. Weather and Forecasting, 11(3), 372-384.

Search Technology. (2000). A pilot-centered turbulence assessment and monitoring system, TAMS, Phase II Final Report. Norcross, GA.

Shapiro, M. (1976). The role of turbulent heat flux in the generation of potential vorticity in the vicinity of upper-level jet stream systems. Monthly Weather Review, 104(7), 892-906.

Shapiro, M. (1978). Further evidence of the mesoscale and turbulent structure of upper level jet stream-frontal zone systems. Monthly Weather Review, 106(8), 1100-1111.

Shapiro, M. (1980). Turbulent mixing within tropopause folds as a mechanism for the exchange of chemical constituents between the stratosphere and troposphere. Journal of the Atmospheric Sciences, 37(5), 994-1004.

Sharman, R., Trier, S., Lane, T., \& Doyle, J. (2012). Sources and dynamics of turbulence in the upper troposphere and lower stratosphere: A review. Geophysical Research Letters, 39(12), L12803.

Sharman, R., \& Lane, T. (2016). Aviation turbulence: Processes, detection, prediction. Berlin: Springer.

Sharman, R., \& Pearson, J. (2017). Prediction of energy dissipation rates for aviation turbulence. Part I: Forecasting nonconvective turbulence. Journal of Applied Meteorology and Climatology, 56(2), 317-337.

Sharman, R., Tebaldi, C., Wiener, G., \& Wolff, J. (2006). An integrated approach to mid-and upper-level turbulence forecasting. Weather and Forecasting, 21(3), 268-287.

Storer, L., Williams, P., \& Joshi, M. (2017). Global response of clear-air turbulence to climate change. Geophysical Research Letters, 44(19), 9976-9984.

Tenenbaum, J. (1991). Jet stream winds: Comparisons of analyses with independent aircraft data over southwest Asia. Weather and Forecasting, 6(3), 320-336.

Trier, S. B., \& Sharman, R. D. (2009). Convection-permitting simulations of the environment supporting widespread turbulence within the upper-level outflow of a mesoscale convective system. Monthly Weather Review, 137(6), 1972-1990.

Trier, S. B., Sharman, R. D., \& Lane, T. P. (2012). Influences of moist convection on a cold-season outbreak of clear-air turbulence (CAT). Monthly Weather Review, 140(8), 2477-2496.

Truscott, B. (2000). EUMETNET AMDAR AAA AMDAR Software Developments Technical Specification. Doc. Ref. E_AMDAR/TSC/003. Met Office: Exeter, UK.

Turner, J. (1999). Development of a mountain wave turbulence prediction scheme for civil aviation. Met Office Forecasting Research Technical Report, p. 265.

Williams, P. D., Read, P., \& Haine, T. (2003). Spontaneous generation and impact of inertia-gravity waves in a stratified, twolayer shear flow. Geophysical Research Letters, 30(24), 2255.

Williams, P. D. (2016). Transatlantic flight times and climate change. Environmental Research Letters, 11(2), 024008.

Williams, P. D. (2017). Increased light, moderate, and severe clearair turbulence in response to climate change. Advances in Atmospheric Sciences, 34(5), 576-586.

Williams, P. D., Haine, T. W., \& Read, P. L. (2005). On the generation mechanisms of short-scale unbalanced modes in rotating two-layer flows with vertical shear. Journal of Fluid Mechanics, 528, 1-22.

Williams, P. D., Haine, T. W., \& Read, P. L. (2008). Inertiagravity waves emitted from balanced flow: Observations, properties, and consequences. Journal of the Atmospheric Sciences, 65(11), 3543-3556.

Williams, P. D., \& Joshi, M. J. (2013). Intensification of winter transatlantic aviation turbulence in response to climate change. Nature Climate Change, 3, 644-648.

Wimmers, A., Griffin, S. M., Bachmeier, A. S., Gerth, J., \& Lindstrom, S. (2018). Resolving gravity waves with Himawari-8 and GOES-16 imagery at the new limit of resolution and the application to aircraft-scale turbulence. In: Sixth aviation, range, and aerospace meteorology special symposium, Austin, TX: American Meteorological Society.

WMO. (2003). Aircraft meteorological data relay (AMDAR) reference manual.

Wolff, J., \& Sharman, R. (2008). Climatology of upper-level turbulence over the contiguous united states. Journal of Applied Meteorology and Climatology, 47(8), 2198-2214.

Wurtele, M., Sharman, R., \& Datta, A. (1996). Atmospheric lee waves. Annual Review of Fluid Mechanics, 28(1), 429-476. 